\title{
HBV and HCV Coinfection among HIV/AIDS Patients in the National Hospital of Tropical Diseases, Vietnam
}

\author{
Bùi Vũ Huy, ${ }^{1}$ Kanxay Vernavong, ${ }^{1}$ and Nguyễn Văn Kính ${ }^{2}$ \\ ${ }^{1}$ Hanoi Medical University, Hanoi 10000, Vietnam \\ ${ }^{2}$ National Hospital of Tropical Diseases, 78 Giai Phong Road, Dong Da District, Hanoi 10000, Vietnam \\ Correspondence should be addressed to Bùi Vũ Huy; dr.vuhuy@yahoo.com
}

Received 25 May 2014; Revised 8 September 2014; Accepted 3 October 2014; Published 8 December 2014

Academic Editor: Robert R. Redfield

Copyright (c) 2014 Bùi Vũ Huy et al. This is an open access article distributed under the Creative Commons Attribution License, which permits unrestricted use, distribution, and reproduction in any medium, provided the original work is properly cited.

\begin{abstract}
Aim. To examine prevalence and characterization of HBV and HCV coinfection among HIV/AIDS patients. Methods. This crosssectional, retrospective study analyzed 724 HIV/AIDS patients in the HIV clinic at the National Hospital of Tropical Diseases (NHTD), from 5/2005 to 4/2011. Results. The prevalence of HBV, HCV, and HIV coinfection was 50.3\% (364/724), of which HbsAg, $\mathrm{HCV}$, and both of $\mathrm{HbsAg}$, and $\mathrm{HCV}$ positivity were $8.4 \%, 35.4 \%$, and 6.5\%, respectively. The cohort (364 patients) with $\mathrm{HBV}$, HCV, and HIV coinfection live in the 30 provinces/cities in the North and Central area of Vietnam. We found statistically significant associations between heightened risk of coinfection with HIV and HCV in the age group 30-39 years $(P<0.001)$, male gender $(P<0.001)$, never married patients $(P<0.001)$, patients with a history of injection drug use $(P<0.001)$, and clinical stages 2-4 $(P<0.001)$. Coinfection with HBV/HIV was statistically significant associations between heightened risk of marital status (never married) $(P<0.001)$ and those who reported transmission through sexual intercourse. Conclusion. Coinfection with viral hepatitis is common in HIV patients; further study of the impact and evolution of coinfection is necessary to find effective treatment algorithms.
\end{abstract}

\section{Introduction}

Hepatitis B virus (HBV) and hepatitis C Virus (HCV) are among the primary causes of morbidity and mortality in HIV patients. Coinfection of HBV and HCV with HIV has been associated with reduced survival, increased risk of progression to liver disease, and increased risk of hepatotoxicity, associated with antiretroviral therapy [1-3].

$\mathrm{HBV}$ and $\mathrm{HCV}$ share common pathways of transmission with HIV, including injection drug use, sexual intercourse, and mother-to-child transmission $[3,4]$. In the past few years, several guidelines and reviews have highlighted this problem and have provided recommendations about how to best manage patients coinfected with HIV and HBV, HCV [3-6].

However, studies showed that the prevalence of HBV, $\mathrm{HCV}$, and HIV coinfection differs both by geographic region and according to behaviour of infected people $[3,4,7,8]$.

In Vietnam, previous studies have reported various prevalence values of HBV, HCV, and HIV coinfection. These studies were evaluated in different provinces and in individuals with different risk factors $[9,10]$, even assessed on blood samples stored [11]. According to these reports, in Bac Ninh province the HIV, HBV, and HCV prevalence was $42.4 \%$, $80.9 \%$, and $74.1 \%$ in injection drug user [9]; in Hai Phong city the cumulative $\mathrm{HBV}$ incidence rate was $53.2 \%$ in drug users, $51.6 \%$ in female sex workers, $54.3 \%$ in seafarers, and $50.5 \%$ in pregnant women [10].

National Hospital of Tropical Diseases (NHTD) is located in Hanoi, that is, a center hospital for infectious diseases in Viet Nam, including HIV/AIDS. Hospitalization patients come from regions of Vietnam, mostly from the Northern and the Central area of Vietnam. HIV/AIDS patients have been managing since the year 2003 at the outpatient clinic. These patients are being cared for and treated according to guidelines of WHO, including diagnosis, treatment (HIV, opportunity infection, and related diseases), and prophylaxis [3].

To examine the prevalence of hepatitis virus in HIV patients, this analysis aimed to assess the seroprevalence of HBsAg and HCV seropositivity within the HIV positive 
population in an HIV outpatient clinic at the NHTD and to identify demographic factors associated with $\mathrm{HBV}$ and $\mathrm{HCV}$ coinfection.

\section{Methods}

2.1. Study Design. This cross-sectional retrospective study aims to evaluate the prevalence of serological markers for $\mathrm{HBV}$ and $\mathrm{HCV}$ infections.

2.2. Studied Population. In the present study, all adult patients with HIV positive who have been managed in outpatient clinic of NHTD were analysed.

The sample included all adult patients aged 18 years or older attending for care and treatment HIV/AIDS during the period from 5/2005 to 4/2011, and patients who received highly active antiretroviral therapy (HAART) were included.

2.3. Data Collection. All of HIV patients were exploiting demographic assessment of clinical signs, opportunity infections, clinical stage classification, screening HBV, HCV, tuberculosis, and counted CD4 when they registered at outpatient clinic. The follow-up visits were done every month and CD4 count was repeated every 6 months. Patients were started on HAART based on CD4 count and clinical stage, in accordance with WHO guidelines [3].

In the study, data on patient demographics and features of HBV and HCV coinfection were collected and analyzed. Data collected on patients included sex, age, reported HIV transmission, $\mathrm{HBV}$ and $\mathrm{HCV}$ status, and AIDS-defining illnesses.

Definitions. (i) HBV/HIV coinfection was defined by a positive $\mathrm{HBV}$ surface antigen (HBsAg).

(ii) $\mathrm{HCV} / \mathrm{HIV}$ coinfection was defined by a positive $\mathrm{HCV}$ antibody.

(iii) Prevalence of HBV coinfection, HCV coinfection, and $\mathrm{HBV} / \mathrm{HCV}$ coinfection was calculated for those with recorded test results for $\mathrm{HBsAg}$ and $\mathrm{HCV}$ antibody.

Risk factors for coinfection with $\mathrm{HBV}$ and $\mathrm{HCV}$ were determined in cross-sectional analyses using Student's $t$-test for trend. Comparisons of proportions were analyzed using Chi-square tests. Significance was set at $P<0.05$.

Stata software version 12.1 was used for all statistical analyses.

This study was approved by the Ethics Committee in Human Research at the NHTD.

\section{Results}

We reviewed data on $724 \mathrm{HIV}$ positive patients treated at the HIV outpatient clinic in NHTD during the study period. Of these, $364(50.3 \%)$ were determined to be coinfected. Of these, 61/724 were seropositive for only HBV (8.4\%), 256/724 were seropositive for only HCV (35.4\%), and 47 were seropositive for both HCV and HBV (6.5\%).

The demographics, risk behaviors, and clinical stage at baseline of HIV positive population coinfection with $\mathrm{HBV}$ and HCV are shown in Table 1.
3.1. Age. There was a significant relationship between age and HCV coinfection rate with the group aged 30-39 years which is at higher risk than other age groups $(P<0.001)$. Finally, HBV coinfection and combined HBV and HCV coinfection in HIV positive patients were not statistically significant with respect to age group.

3.2. Gender. Regarding gender, there was a significant association $(P<0.001)$ between HCV only coinfection in HIV positive men compared with HIV positive women $(50.3 \%$ and $8.5 \%$, resp.); there were no differences between genders in rates of coinfection with $\mathrm{HBV}$ in HIV positive patients $(7.3 \%$ and $10.4 \%$, resp.). Finally, HBV/HCV coinfections in HIV positive men were higher than the HIV positive women $(9.5 \%$ and $1.2 \%$, resp.).

3.3. Marital Status. Marital status and HBV, HCV, and HIV coinfections status were significantly associated. The rates of $\mathrm{HBV}$ and $\mathrm{HCV}$ coinfection in HIV positive patients were higher among unmarried people than married people.

3.4. Geographic Domicile. The vast majority of HIV positive patients lived in Hanoi (40.9\% [296/724]). Among the 724 HIV positive patients at outpatient clinic, the cohort (364 patients) with HBV, HCV, and HIV coinfection lived in the 30 provinces and cities in the North and Central area of Vietnam, and one-third live in the city of Hanoi (125/364).

3.5. Risk Factors Associated with Transmission Behaviours. A significant relationship was found between exposure to transmission risk factors and coinfection with either $\mathrm{HCV}$ or HBV $(P<0.001)$. In the HCV and HIV coinfection group, injection drug use had the strongest association (44\% versus $28 \%$ and $12.2 \%$ resp.). Risk for HBV coinfection was the highest in the group identified as transmission by sexual intercourse (26\% and $4 \%$, resp.). However, risk for $\mathrm{HBV} / \mathrm{HCV}$ coinfection in HIV positive patients was significantly associated with behaviors combining injection drug use and sexual intercourse.

3.6. Clinical Stage Classification. Based on clinical staging, the rate of $\mathrm{HBV}$ coinfection was not different in those with clinical stage. But the rates of $\mathrm{HCV} / \mathrm{HIV}$ coinfections and $\mathrm{HBV} / \mathrm{HCV} / \mathrm{HIV}$ coinfection were higher in clinical stages 2 and $3(P<0.001)$.

\section{Discussion}

4.1. Prevalence of Hepatitis $B$ and $C$ Viruses and HIV CoInfection. Overall, the prevalence of hepatitis $\mathrm{B}$, hepatitis $\mathrm{C}$, or both, with HIV coinfection, is $50.3 \%$. Among these, $\mathrm{HBV} / \mathrm{HIV}$ is $8.4 \%, \mathrm{HCV} / \mathrm{HIV}$ is $35.4 \%$, and $\mathrm{HBV} / \mathrm{HCV} / \mathrm{HIV}$ is $6.5 \%$. We did not assess prevalence of other hepatitis viruses in the HIV positive population, such as hepatitis A, hepatitis $\mathrm{D}$, and hepatitis E. Varied prevalence rates of hepatitis and HIV coinfection have been reported by study by country, as well as by hepatitis subtype $[7,8,10]$. Overall, the prevalence of $\mathrm{HCV} / \mathrm{HIV}$ is considerably higher than $\mathrm{HBV} / \mathrm{HIV}$ and it 
TABLE 1: Demographic, risk behaviors, and clinical stage at baseline of the studied population $(n=724)$.

\begin{tabular}{|c|c|c|c|c|c|c|c|}
\hline & \multirow{2}{*}{$\begin{array}{c}\text { Overall sample } \\
N(\%)\end{array}$} & \multicolumn{2}{|c|}{ HBV infection } & \multicolumn{2}{|c|}{ HCV infection } & \multicolumn{2}{|c|}{$\mathrm{HBV} / \mathrm{HCV}$ infection } \\
\hline & & Number of pos (\%) & $P$ & Number of pos (\%) & $P$ & Number of pos (\%) & $P$ \\
\hline \multicolumn{8}{|l|}{ Demographic } \\
\hline \multicolumn{8}{|l|}{ Age group (years) } \\
\hline$<30$ & $168(23.2)$ & $11(6.5)$ & \multirow{4}{*}{0.70} & $32(19.0)$ & \multirow{4}{*}{$<0.001$} & $10(6.0)$ & \multirow{4}{*}{0.23} \\
\hline $30-39$ & $375(51.8)$ & $32(8.5)$ & & $189(50.4)$ & & $30(8.0)$ & \\
\hline $40-49$ & $116(16.0)$ & $11(9.5)$ & & $24(20.7)$ & & $6(5.2)$ & \\
\hline$\geq 50$ & $65(9.0)$ & $7(10.8)$ & & $11(16.9)$ & & $1(1.5)$ & \\
\hline \multicolumn{8}{|l|}{ Sex } \\
\hline Male & $465(64.2)$ & $34(7.3)$ & \multirow{2}{*}{0.15} & $234(50.3)$ & \multirow{2}{*}{$<0.001$} & $44(9.5)$ & \multirow{2}{*}{$<0.001$} \\
\hline Female & $259(35.8)$ & $27(10.4)$ & & $22(8.5)$ & & $3(1.2)$ & \\
\hline \multicolumn{8}{|l|}{ Marital status } \\
\hline Never married & 98 (13.5) & $45(45.5)$ & \multirow{3}{*}{$<0.001$} & $69(70.4)$ & \multirow{3}{*}{$<0.001$} & $10(10.2)$ & \multirow{3}{*}{$<0.04$} \\
\hline Currently married & $543(75.0)$ & $14(2.6)$ & & $182(33.5)$ & & $36(6.6)$ & \\
\hline Divorced/widowed & $83(11.5)$ & $2(2.4)$ & & $5(6.0)$ & & $1(1.2)$ & \\
\hline \multicolumn{8}{|l|}{ Geographic Domicile } \\
\hline Hanoi & $296(40.9)$ & $18(6.1)$ & \multirow{2}{*}{0.06} & $91(30.7)$ & \multirow{2}{*}{0.13} & $16(5.4)$ & \multirow{2}{*}{0.32} \\
\hline Other provinces & $428(59.1)$ & $43(10.0)$ & & $155(36.2)$ & & $31(7.2)$ & \\
\hline \multicolumn{8}{|l|}{ Risk factor associated } \\
\hline Injection drug used & $443(61.2)$ & $18(4.0)$ & \multirow{3}{*}{$<0.001$} & $195(44.0)$ & \multirow{3}{*}{$<0.001$} & $24(5.0)$ & \multirow{3}{*}{$<0.001$} \\
\hline Sexual intercourse & $165(22.8)$ & $43(26.0)$ & & $46(27.9)$ & & $5(3.0)$ & \\
\hline Mixed & $116(16.0)$ & $0(0)$ & & $15(11.2)$ & & $18(15.5)$ & \\
\hline \multicolumn{8}{|l|}{ Clinical stage classification } \\
\hline Stage 1 & $262(27.6)$ & $23(8.8)$ & \multirow{4}{*}{0.27} & 47 (17.9) & \multirow{4}{*}{$<0.001$} & $14(5.3)$ & \multirow{4}{*}{$<0.001$} \\
\hline Stage 2 & $132(18.2)$ & $16(12.1)$ & & $63(47.7)$ & & $9(6.8)$ & \\
\hline Stage 3 & $74(10.2)$ & $6(8.1)$ & & $31(41.9)$ & & $12(16.2)$ & \\
\hline Stage 4 & $256(35.4)$ & $16(6.2)$ & & 115 (44.9) & & $12(4.7)$ & \\
\hline
\end{tabular}

is higher than those in industrialized countries [12]. With respect to $\mathrm{HCV}$ coinfection, our rates differ from some crosssectional studies in Vietnam which have reported the prevalence of $\mathrm{HCV} / \mathrm{HIV}$ that ranges from $74 \%$ [11] to $100 \%$ [9], findings that are similar to those reported from China which range from 62.4 to $93.6 \%$ in HIV-positive intravenous drug users [13]. These studies contrast with the very low prevalence reported in a study from India of $2 \%$, where the predominant mode of acquiring HIV infection was $80 \%$ heterosexual contact, $6 \%$ transfusion of blood products, and $2.43 \%$ intravenous drug use [7]. It also varies from reports from an industrialized country, such as Australia (13.1\%) [12]. However, the prevalence of $\mathrm{HBV}$ in our study is similar to other studies in Vietnam [11], in developing countries [7], and in industrialized countries [12].

We hypothesize that differences seen in the prevalence of different strains of hepatitis viruses relate to the population studied, transmission risk behaviours of the population, and the impact of harm reduction activities $[3,10]$. A case-control study on risks for $\mathrm{HIV}, \mathrm{HBV}$, and $\mathrm{HCV}$ infections among male injection drug users in northern Vietnam showed that $64 \%$ of these IDUs share needles, drug solutions, containers, rinse water, and frontloading drugs [9]. Among them, only
$12 \%$ reported never having had sexual intercourse and only half of the male IDUs reported using a condom at their last sexual intercourse. The model was significantly associated with $\mathrm{HIV}$ infection $(\mathrm{OR}=2.8)$, HBV infection $(\mathrm{OR}=3.8)$, and $\mathrm{HCV}$ infection $(\mathrm{OR}=4.6)$. In another report in Vietnam, the authors showed that the prevalence of hepatitis B (HBsAg) ranged from $5.7 \%$ to $24.7 \%$ and anti-HCV ranged from $0.38 \%$ to $4.3 \%$ in the general population, while anti-HCV among IDUs ranged from $31 \%$ to $97.2 \%$. The HBV prevalence among HIV population was similar to the general population, while $\mathrm{HCV} / \mathrm{HIV}$ coinfection was concentrated in some groups and it can be as high as $98.5 \%$ among HIV-infected patients [14].

Prevention of hepatitis B and hepatitis C infections among HIV-infected patients in Vietnam has been of interest to public health authorities. No surveillance system is in place to monitor infection levels. No program exists to provide HIV persons with information on viral hepatitis infections and how to prevent them, nor are intervention programs available to provide necessary skills for avoiding infections. Standard needle and syringe exchange programs have been shown to be effective in preventing HIV transmission, but findings on these programs' effectiveness in $\mathrm{HCV}$ prevention are inconclusive. 
4.2. Demographic Characteristic of HBV, HCV, and HIV Coinfected People. In this study, rates of $\mathrm{HBV} / \mathrm{HIV}$ coinfection and $\mathrm{HBV} / \mathrm{HCV} / \mathrm{HIV}$ coinfection did not differ significantly in the age groups. However, rate of coinfection was significantly higher in the group aged $30-39$ years $(P<0.001)$ in the $\mathrm{HCV} / \mathrm{HIV}$ coinfection group. Here, too, the rate of hepatitis and HIV coinfection across different age groups has been reported to be widely different across studies and countries. As we found, reported rates of coinfection are considerably higher in the age group of 30-40 years in some studies from developing countries [7], while rates in industrialized countries were the highest in the age group aged over 40 years [12]. We hypothesize that the decline in rates of hepatitis/HIV coinfection in the age group over 40 years may be related to increased loss to follow-up, caused by the end-stage liver disease complication [6]. This should be of interest because it may be the reason for the limited HAART for the HIV positive population. This hypothesis should be investigated in a future study.

Independent risk behaviour for $\mathrm{HBV}$ and $\mathrm{HCV}$ coinfection was found in our study. As is known, both HBV infection and HCV infection share transmission routes, in particular parenteral exposure. HCV/HIV coinfection is more closely associated with injection drug use $(P<0.001)$, while HBV/ HIV coinfection is more closely associated with sexual intercourse $(P<0.001)$. In addition, $\mathrm{HCV} / \mathrm{HIV}$ and $\mathrm{HBV} / \mathrm{HCV} /$ HIV coinfection are significantly higher in males than females $(P<0.001)$, but we do not see a statistically significant difference between sexes in HBV/HIV coinfection. IDUs in Vietnam were reported sharing needles, drug solutions, containers, and rinse water and have been significantly associated with HIV infection, HBV infection, and HCV infection in a prior study [9]. Prior research in Vietnam suggests that HIV transmission routes are highest from injection drug use $[10,11]$ particularly in men [11]. Demographic studies of hepatitis and HIV coinfection also showed that HCV/HIV coinfection was more common in injection drug users and more common in men than women [12]. Our study of this outpatient clinic population showed that most HIV positive patients have families (75\%) and common domicile for patients with hepatitis and HIV coinfection is Hanoi (40.9\%). However, group patients with hepatitis and HIV coinfection distribute in $30 / 63$ provinces/cities of Vietnam and may be the source of infection in the community. Taken together, these factors suggest that this urban-dwelling, family-connected IDU population is a good target for an intervention strategy to prevent coinfection or transmission of either hepatitis or HIV.

Limitations of our report are as follows. This was a retrospective review of HIV patients, including all of patients participating in treatment of HIV/AIDS in the outpatient clinic of NHTD, in the period from 2005 to 2011. This subpopulation of the clinic is not representative of all HIV patients in the clinic or all HIV patients in Vietnam. Nonetheless, our results are consistent with other studies and are relevant for improving the care of HIV/AIDS patients.

\section{Conclusion}

Coinfection with viral hepatitis is common in HIV patients. Therefore, reducing parenteral transmission of $\mathrm{HCV}$ and
HBV requires that current prevention messages be revised to alert HIV person to the relevant risks factors, including emphasis on the importance of reducing or eliminating all equipment-sharing practices and safe sexual activity. A good target for a targeted intervention strategy to prevent hepatitis $B$, hepatitis C, and HIV coinfection could be based on family and community. Consideration should be paid to integrating hepatitis B vaccination for IDUs into large-scale HIV prevention programs. All HIV-infected persons should be supported in a program of routine $\mathrm{HBV}$ and $\mathrm{HCV}$ screening testing. We should continue to find out more about the impact and evolution of coinfection.

\section{Conflict of Interests}

The authors declare that there is no conflict of interests regarding the publication of this paper.

\section{Acknowledgments}

National Hospital of Tropical Diseases and HIV OPC in National Hospital of Tropical Diseases accommodated the authors with the HBV, HCV, and HIV data. Dr. Nguyen Van Kinh, director of hospital, helped them to work on this research.

\section{References}

[1] L. Highleyman, "HIV/HBV and HIV/HCV coinfected people with impaired liver function and inflammation have higher risk of non-AIDS death," in Proceedings of the 17th Conference on Retroviruses and Opportunistic Infections (CROI '10), San Fransisco, Calif, USA, February 2010.

[2] E. Rosenthal, M. Poirée, C. Pradier et al., "Mortality due to hepatitis C-related liver disease in HIV-infected patients in France (Mortavic 2001 study)," AIDS, vol. 17, no. 12, pp. 18031809, 2003.

[3] WHO, Consolidated Guidelines on the Use of Antiretroviral Drugs for Treating and Preventing HIV Infection: Recommendations for a Public Health Approach, 2013.

[4] P. Nelson, B. Mathers, B. Cowie et al., "The epidemiology of viral hepatitis among people who inject drugs: results of global systematic reviews," The Lancet, vol. 378, no. 9791, pp. 571-583, 2011.

[5] R. Ranjbar, A. Davari, M. Izadi, N. Jonaidi, and S. Alavian, "HIV/HBV co-infections: epidemiology, natural history, and treatment: a review article," Iranian Red Crescent Medical Journal, vol. 13, no. 12, pp. 855-862, 2011.

[6] V. Soriano, P. Barreiro, and M. Nuñez, "Management of chronic hepatitis B and C in HIV-coinfected patients," Journal of Antimicrobial Chemotherapy, vol. 57, no. 5, pp. 815-818, 2006.

[7] S. Gupta and S. Singh, "Hepatitis B and C virus co-infections in human immunodeficiency virus positive North Indian patients," World Journal of Gastroenterology, vol. 12, no. 42, pp. 6879-6883, 2006.

[8] A. Tremeau-Bravard, I. C. Ogbukagu, C. J. Ticao, and J. J. Abubakar, "Seroprevalence of hepatitis B and C infection among the HIV-positive population in Abuja, Nigeria," African Health Sciences, vol. 12, no. 3, pp. 312-317, 2012. 
[9] V. M. Quan, V. F. Go, L. V. Nam et al., "Risks for HIV, HBV, and HCV infections among male injection drug users in northern Vietnam: a case-control study," AIDS Care-Psychological and Socio-Medical Aspects of AIDS/HIV, vol. 21, no. 1, pp. 7-16, 2009.

[10] C. H. Nguyen, A. Ishizaki, P. T. T. Chung et al., "Prevalence of HBV infection among different HIV-risk groups in Hai Phong, Vietnam," Journal of Medical Virology, vol. 83, no. 3, pp. 399404, 2011.

[11] V. T. Vân, N. T. Hạnh, N. X. Quang, N. N. Điệp, and L. K. Trâm, "Preliminary studies on co-infection of hepatitis B virus, hepatitis C virus in patients with HIV (+) at Bach Mai Hospital," Proceedings of Scientific Research Works in Bach Mai Hospital 2001-2002, pp. 471-478, 2003.

[12] D. Lincoln, K. Petoumenos, G. J. Dore et al., "HIV/HBV and $\mathrm{HIV} / \mathrm{HCV}$ coinfection, and outcomes following highly active antiretroviral therapy," HIV Medicine, vol. 4, no. 3, pp. 241-249, 2003.

[13] X. Chen, J.-M. He, L.-S. Ding, G.-Q. Zhang, X.-B. Zou, and J. Zheng, "Prevalence of hepatitis $B$ virus and hepatitis $C$ virus in patients with human immunodeficiency virus infection in central China," Archives of Virology, vol. 158, no. 9, pp. 18891894, 2013.

[14] L. Sereno, F. Mesquita, M. Kato, D. Jacka, T. T. van Nguyen, and T. N. Nguyen, "Epidemiology, responses, and way forward: the silent epidemic of viral hepatitis and HIV coinfection in Vietnam," Journal of the International Association of Physicians in AIDS Care, vol. 11, no. 5, pp. 311-320, 2012. 


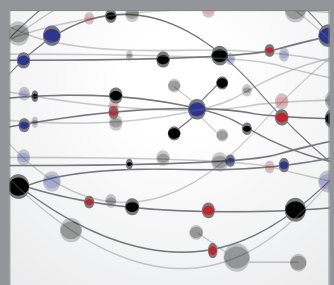

The Scientific World Journal
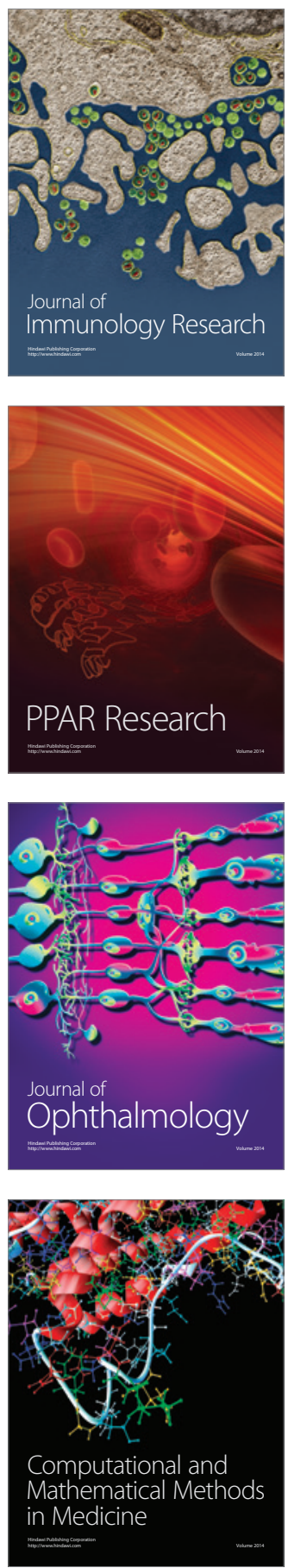

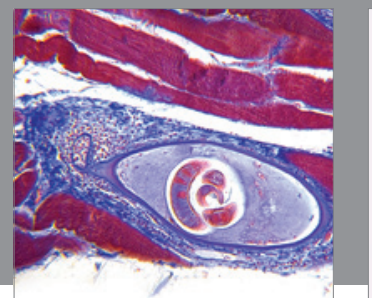

Gastroenterology

Research and Practice
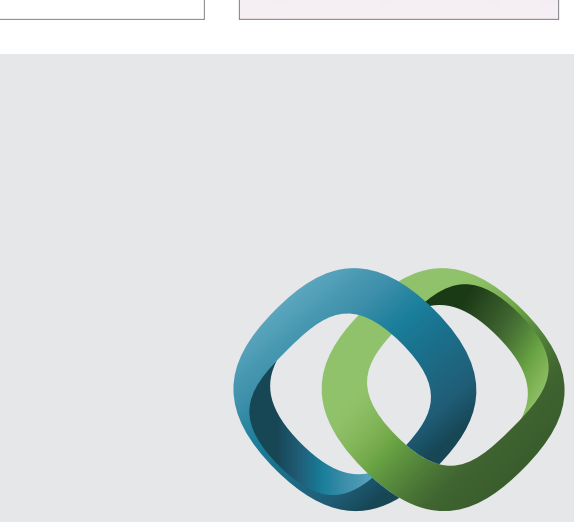

\section{Hindawi}

Submit your manuscripts at

http://www.hindawi.com
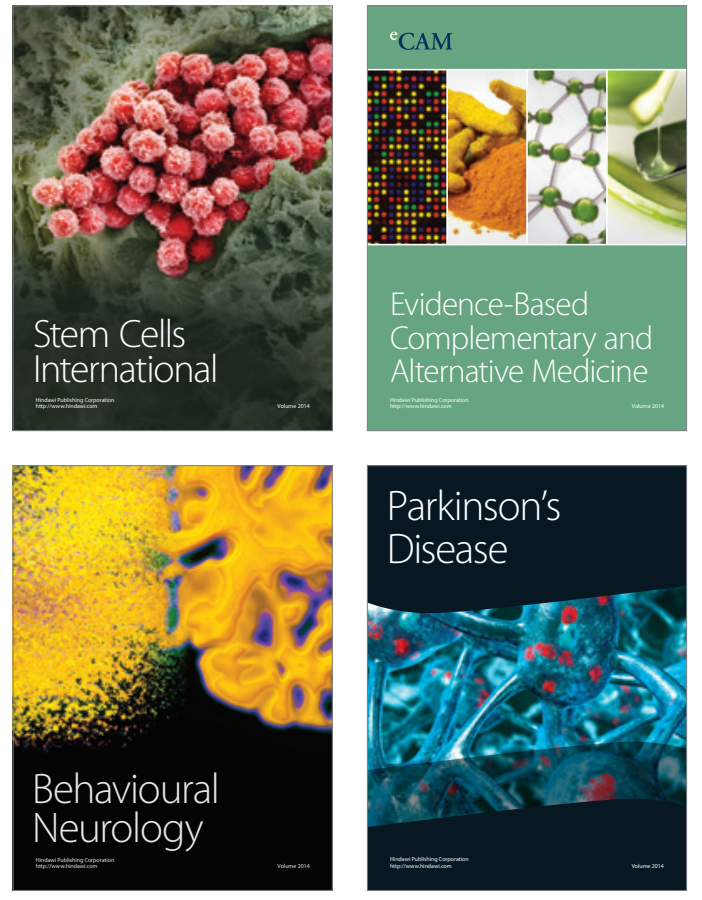
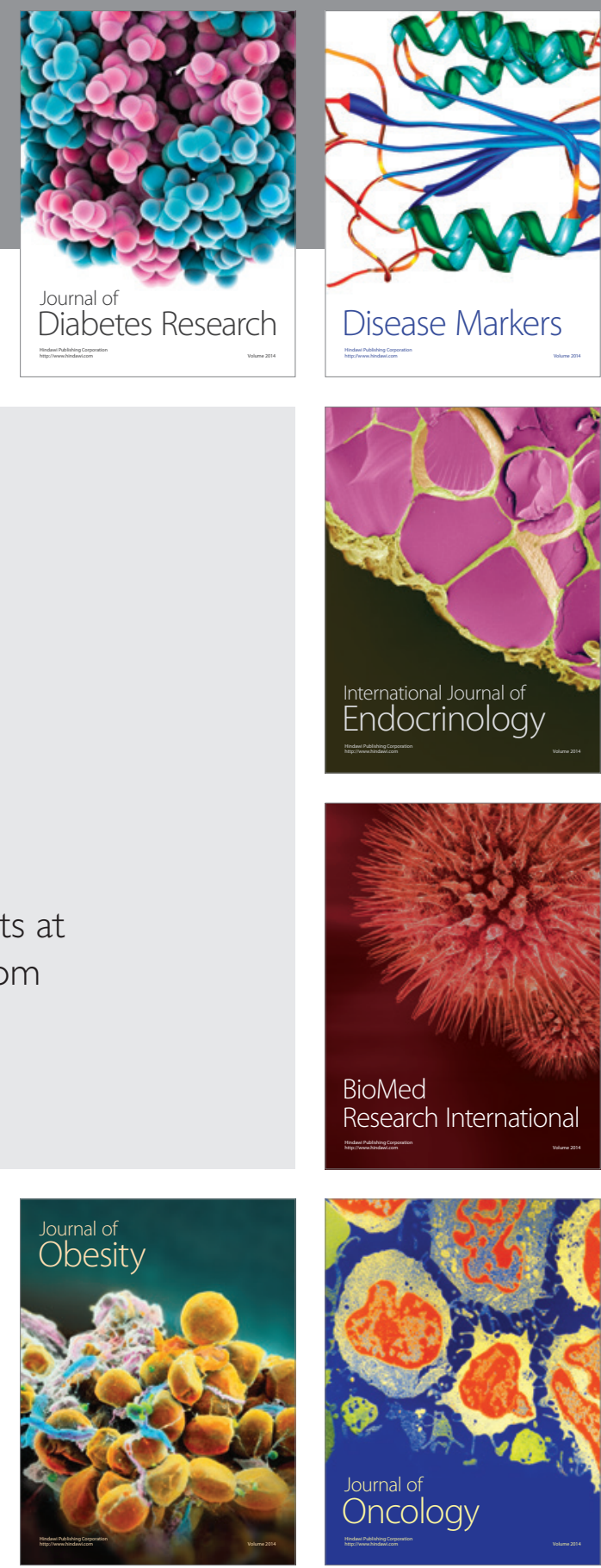

Disease Markers
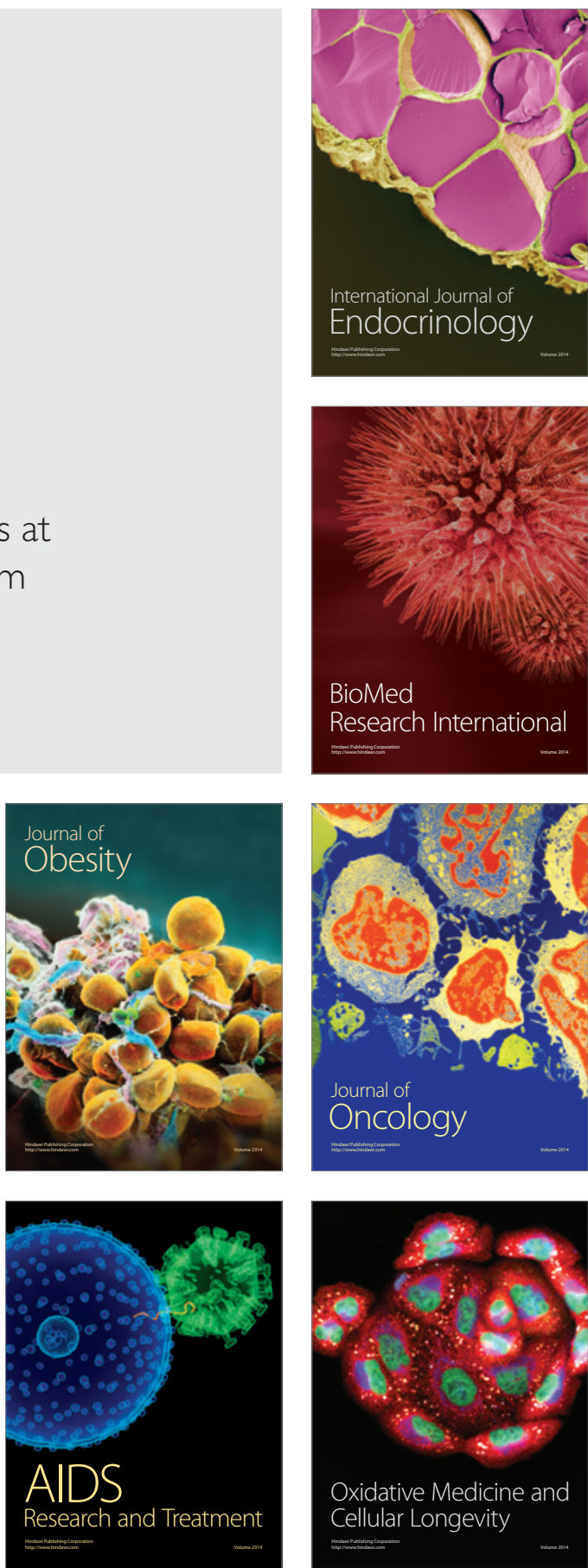